\title{
Neuroendocrine Lung Tumors: Grade Correlates with Proliferation but not Angiogenesis
}

\author{
Zoya K. Arbiser, M.D., Jack L. Arbiser, M.D., Ph.D., Cynthia Cohen, M.D., Anthony A. Gal, M.D. \\ Department of Pathology, Southern Regional Medical Center (ZKA), Riverdale; Department of \\ Dermatology, Emory University Hospital (JLA), Atlanta; and Department of Pathology and Laboratory \\ Medicine, Emory University Hospital (CC, AAG), Atlanta, Georgia
}

\begin{abstract}
Angiogenesis has been implicated in the progression of human neoplasia from benign precursor to invasive and metastatic phenotypes. The acquisition of dominant oncogenes in preneoplastic cells in vitro and in vivo has been associated with the increased ability of tumor cells to secrete angiogenic mediators and recruit blood vessels. However, in a subset of benign lesions, high levels of angiogenesis have been found before the conversion to invasive and metastatic phenotypes. In many of these benign lesions, dominant oncogenic pathways are activated first; then as malignant potential is acquired, there is a loss of nuclear tumor suppressor genes, such as p53 and p16. We studied neuroendocrine lung tumors (NLT) ranging from typical and atypical carcinoid tumors to large cell neuroendocrine and small cell carcinomas in order to determine whether angiogenesis (as assessed by mean vessel density) and proliferation rates (as assessed by MIB-1 nuclear immunohistochemical staining) correlate with tumor type. We found that increased rates of proliferation, but not angiogenesis, correlate with tumor type. The association of increased proliferation and tumor type may prove to be clinically useful and shed light on the role of sequential oncogenic alterations in NLT.
\end{abstract}

KEY WORDS: Angiogenesis, Atypical carcinoid tumor, Carcinoid tumor, CD-31, Cellular proliferation, MIB-1, Neuroendocrine lung tumor, Small cell carcinoma.

Mod Pathol 2001;14(12):1195-1199

Copyright (C) 2001 by The United States and Canadian Academy of Pathology, Inc.

VOL. 14, NO. 12, P. 1195, 2001 Printed in the U.S.A.

Date of acceptance: August 8, 2001.

Address reprint requests to: Anthony A. Gal, M.D., Department of Pathology and Laboratory Medicine, Emory University Hospital, H-171, 1364 Clifton Road, NE, Atlanta, GA 30322; e-mail: agal@emory.edu; fax: 404-712-4754.
The histologic subtyping of neuroendocrine lung tumors (NLT) is of critical clinical importance. The morphologic spectrum of typical carcinoid tumor (TC), atypical carcinoid tumor (AC), large cell neuroendocrine carcinoma (LCNEC), and small cell carcinoma (SCC) is associated with increased loss of differentiation and aggressive clinical behavior (1). Often, the histologic distinction between TC and AC can be subtle, and numerous classification schemes have been proposed $(2,3)$. Using strict and clarified criteria set forth by Travis et al. (4), the distinction between TC and AC has become increasingly important because of vastly different patient survival data. The 10-year survival of patients with TC is $87 \%$, but this drops dramatically to $35 \%$ for patients with AC. At the opposite end of the NLT spectrum, high-grade neuroendocrine carcinomas (LCNEC and SCC) exhibit morphological diversity, but similar genetic abnormalities $(1,5,6)$.

Differences between low (TC), intermediate (AC), and high-grade (LCNEC and SCC) NLT can be assessed by immunophenotyping for neuroendocrine markers, cell cycle abnormalities, and angiogenesis. In NLT, several studies have shown that increased Ki67 or MIB-1 expression, as a marker of increased proliferation, correlates with histological subtype and may be of prognostic value (7-11). In contradistinction, there have been few studies on angiogenesis in NLT. Slodkowka et al. (12) found no correlation between angiogenesis and the presence of regional lymph node metastases in TC or AC, but the full spectrum of NLT was not assessed. In this study, we analyzed angiogenesis and proliferation rates in the entire spectrum of NLT to shed light on potential differences in tumor biology.

\section{MATERIALS AND METHODS}

Twenty formalin-fixed, paraffin-embedded NLT (5 TC, 5 AC, 5 LCNEC, 5 SCC) were retrieved from the files in the Department of Pathology of Emory University Hospital, Atlanta, Georgia. The tumors were classified by one of the authors (AAG) accord- 

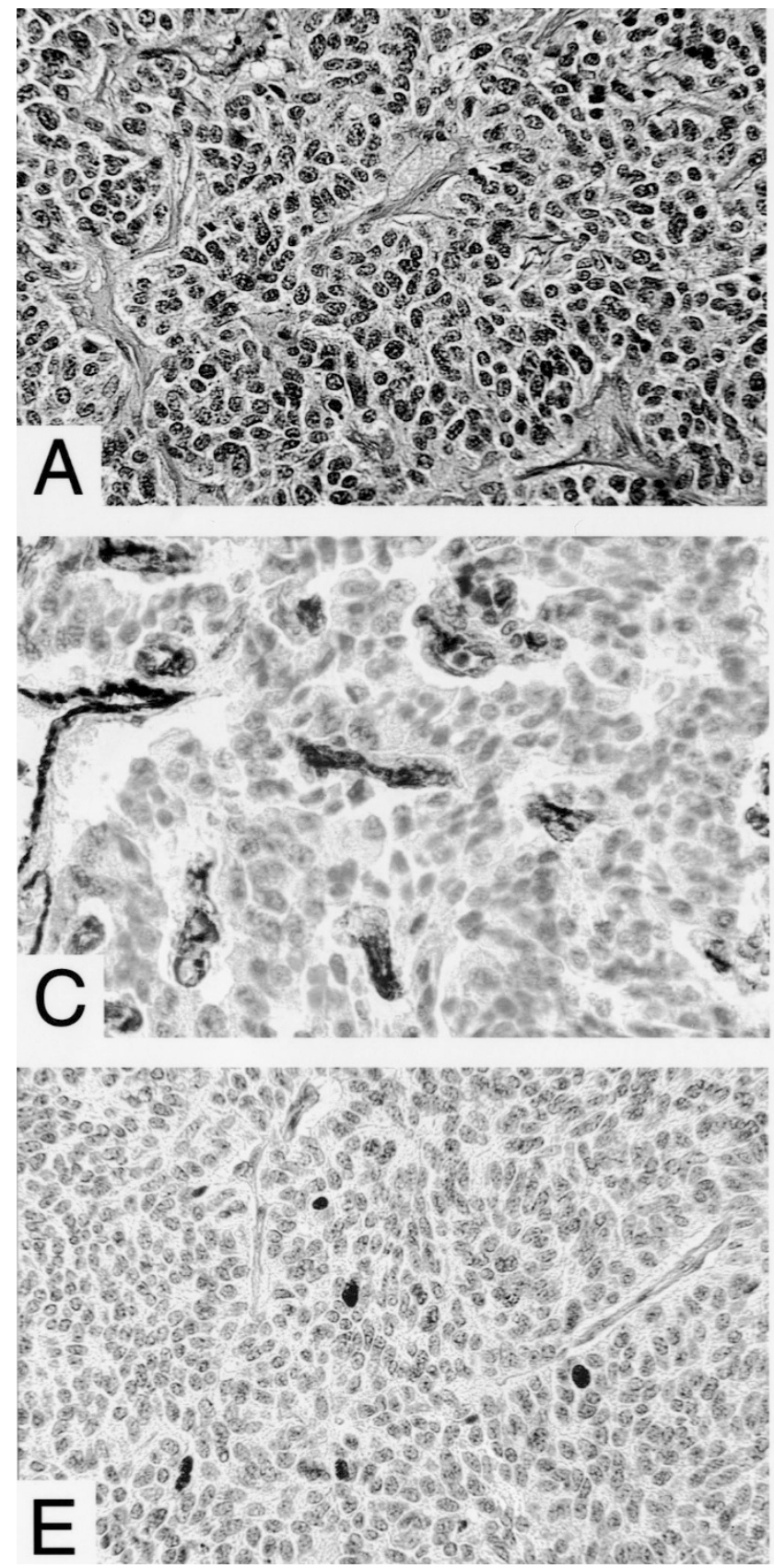
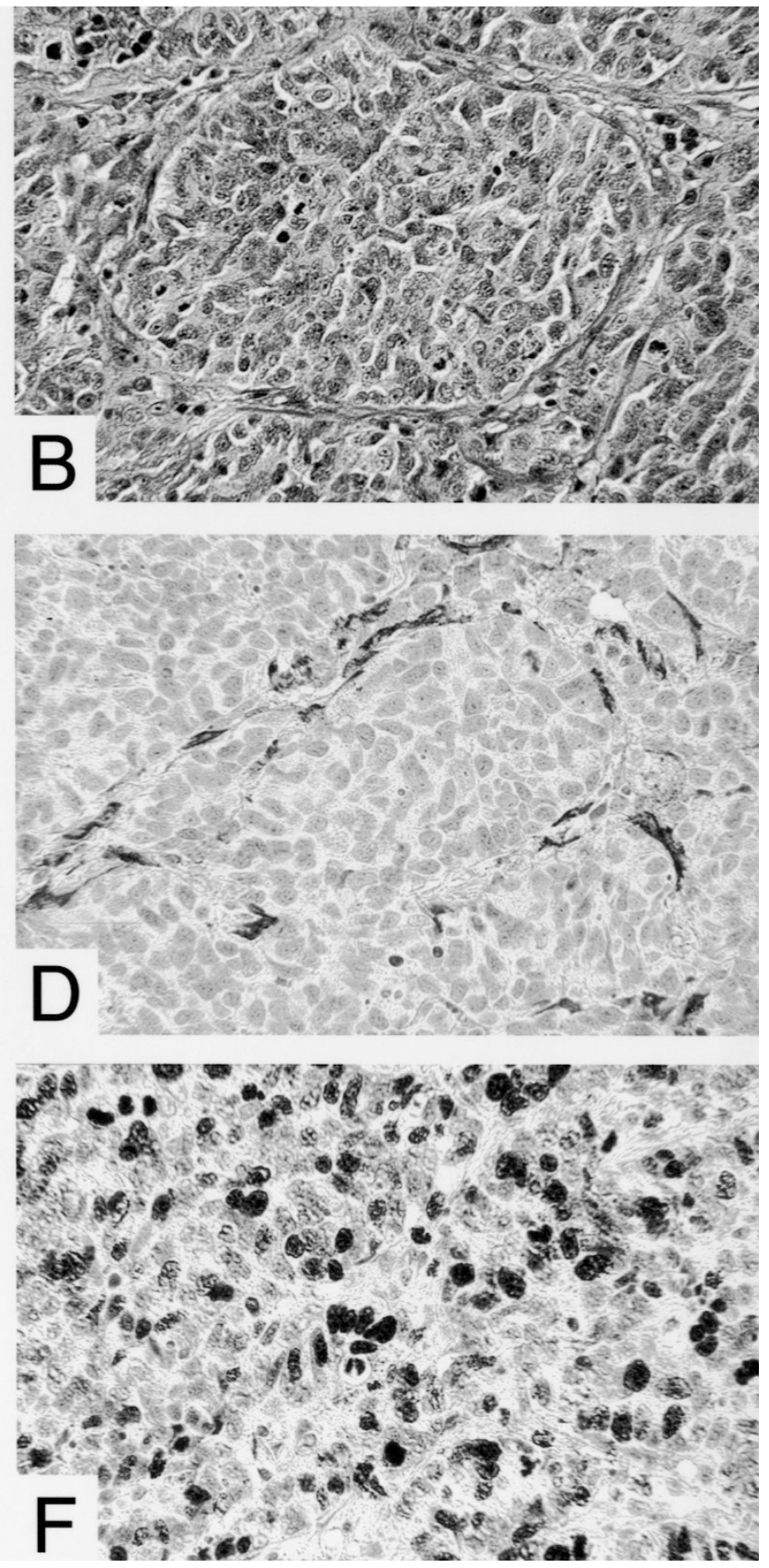

FIGURE 1. A, typical carcinoid tumor, hematoxylin and eosin stain $(100 \times)$. B, large cell neuroendocrine carcinoma, hematoxylin and eosin stain $(100 \times)$. C, typical carcinoid tumor, mean vessel density, CD-31 immunostain $(100 \times)$. D, large cell neuroendocrine carcinoma, mean vessel density, CD-31 immunostain $(100 \times)$. E, typical carcinoid tumor, cellular proliferation, MIB-1 immunostain $(100 \times)$. F, large-cell neuroendocrine carcinoma, cellular proliferation, MIB-1 immunostain $(100 \times)$.

ing to the World Health Organization classification of lung tumors, based on the criteria proposed by Travis et al. for NLT $(4,13)$. The 4 - $\mu \mathrm{m}$ sections were subjected to steam heat-induced epitope retrieval and then immunostained using an avidin-biotin complex technique (Ventana, Tucson, AZ). The cases were stained for CD 31 (DAKO, Carpinteria, CA, 1:50) and MIB-1 (1:50; Immunotech, Westbrook ME). 3,3'-diamino-benzidine was used as chromogen, and hematoxylin as counterstain. Positive controls included myometrium (CD 31) and tonsil
(MIB-1). Negative controls had specific antibody replaced by buffer.

Angiogenesis was assessed by two authors (ZKA and CC) by quantitation of mean vessel density (MVD) in 2 high-power fields $(200 \times)$ in one "hot spot" according to the method described by Weidner et al. (14). Cellular proliferation was assessed by manually counting the number of MIB-1 nuclear-positive cells in a 1000 cell count, converted into a percentage of total cells. All of the cases were scored by a single observer (ZKA). 


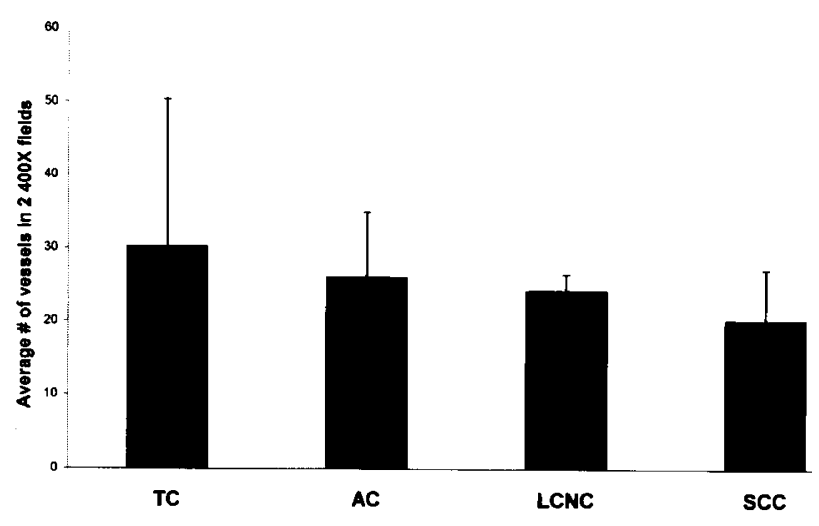

FIGURE 2. Mean vessel density in neuroendocrine lung tumors. TC, typical carcinoid tumor; AC, atypical carcinoid tumor; LCNEC, large-cell neuroendocrine carcinoma; and SCC, small-cell carcinoma.

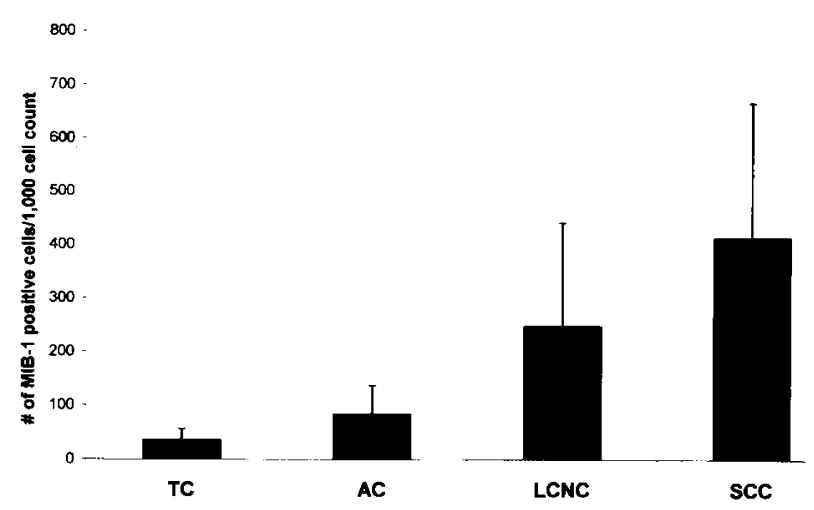

FIGURE 3. Proliferation rates of neuroendocrine lung tumors. TC, typical carcinoid tumor; AC, atypical carcinoid tumor; LCNEC, large-cell neuroendocrine carcinoma; and SCC, small-cell carcinoma.

Analysis of variance was performed using ANOVA.

\section{RESULTS}

Representative photomicrographs of low- (TC) and high-grade NLT (LCNEC) stained with hematoxylin and eosin are depicted in Figure 1, A-B, respectively. The mean MVD was similar in all four tumor types $(P=.395)$ with no statistically significant difference (Fig. 1, C-D; Fig. 2).

Proliferation rates are significantly different between SCC and the three types of carcinoid tumor $(P<.05$; Fig. 1, E-F; Fig. 3). Analysis among the subtypes of carcinoid tumor revealed proliferation rates that were not significantly different. Hence, proliferation rates did not distinguish between TC and AC, nor between SCC and LCNEC. These latter two NLT had much higher proliferation rates than carcinoid tumors, but their rates were not significantly different.

\section{DISCUSSION}

The pathogenesis of NLT is not well understood, despite increasing awareness of their morphologi- cal diversity. The separation of high- from lowgrade NLT is prognostically relevant and generally reproducible among experienced pathologists (3). However, differentiation of intermediate-grade NLT may be diagnostically difficult because AC may demonstrate a propensity to invade and metastasize $(2,4,15)$. To explain differences in clinical behavior, various mechanisms in tumor biology are under investigation.

Angiogenesis is a necessary process in tumor progression (16). Increased angiogenesis is required for tumor growth in animal models, whereas inhibition of angiogenesis results in increased tumor apoptosis and decreased metastases (17). Weidner et al. (14) have shown that microvessel count, a marker of angiogenesis, correlates with clinical outcome in carcinoma of the breast. Since that initial study, numerous studies in other solid tumors have confirmed the role of angiogenesis with tumor progression in vivo and have also confirmed that elevated microvessel counts are associated with poor prognosis $(18,19)$.

The addition of dominant oncogenes in vitro and in vivo to cells with defined mutations in tumor suppressor genes confers an angiogenic phenotype $(20-22)$. These studies parallel the discovery of dominant oncogenes, whose transforming ability was discovered by their ability to convert preneoplastic cells with deletions in tumor suppressor genes into fully malignant and angiogenic neoplasms (23-26). The loss of a nuclear tumor suppressor gene is an early event in the elaborate sequence that leads to tumorigenesis. There are, however, several examples of poorly angiogenic precursor lesions, including those of early squamous cell carcinomas of the skin, cutaneous melanomas, and cervical intraepithelial neoplasia/carcinoma $(27,28)$.

We have shown that NLT with good prognosis, such as TC, are angiogenic, yet they may reach appreciable sizes without clinical evidence of metastatic growth. Other examples of angiogenic neoplasms include angiomyolipomas of tuberous sclerosis (Arbiser et al., submitted), hemangioblastomas of von HippelLindau disease, and Spitz nevi (29-31).

Our study showing that proliferation rate, but not MVD, correlates with NLT subtype and suggests that carcinoid tumors are highly vascular neoplasms with indolent behavior. Proliferative ability in vivo correlates with a progressive degree of cellular atypia and loss of tumor differentiation. Thus, the acquisition of the angiogenic phenotype is an early event, whereas tumor proliferative capabilities appear to be a later event. Recent studies of NLT have shown activation of ras $(32,33)$ or loss of function of menin in a subset of TC to be a common early event in low-grade NLT, whereas loss of p53 is seen in high-grade NLT $(6,32-37)$. 
Two major conclusions can be inferred from our study. First, increased proliferation rates are associated with loss of tumor differentiation, particularly in high-grade NLT, such as in LCNEC and SCC. Second, MVD is not appreciably different among the various NLT tumor types. These observations may be useful prognostically and in the development of novel preventive and therapeutic modalities for certain NLT.

Acknowledgments: The authors thank Diane Lawson and Deborah Sexton for assistance with immunohistochemistry and to thank Robert Santoianni for his photographic expertise.

\section{REFERENCES}

1. Sampietro G, Tomasic G, Collini P, Biganzoli E, Boracchi P, Bidoli $\mathrm{P}$, et al. Gene product immunophenotyping of neuroendocrine lung tumors. No linking evidence between carcinoids and small-cell lung carcinomas suggested by multivariate statistical analysis. Appl Immunohistochem Mol Morphol 2000;8:49-56.

2. Travis WD, Linnoila RI, Tsokos MG, et al. Neuroendocrine tumors of the lung with proposed criteria for large-cell neuroendocrine carcinoma. An ultrastructural, immunohistochemical, and flow cytometric study of 35 cases. Am J Surg Pathol 1991;15:529-53.

3. Travis WD, Gal AA, Colby TV, Klimstra DS, Falk R, Koss MN. Reproducibility of neuroendocrine lung tumor classification. Hum Pathol 1998;29:272-9.

4. Travis WD, Rush W, Flieder DB, Falk R, Fleming MV, Gal AA, et al. Survival analysis of 200 pulmonary neuroendocrine tumors with clarification of criteria for atypical carcinoid and its separation from typical carcinoid. Am J Surg Pathol 1998;22:934-44.

5. Wick MR. Neuroendocrine neoplasia. Current concepts. Am J Clin Pathol 2000;113:331-5.

6. Onuki N, Wistuba II, Travis WD, Virmani AK, Yashima K, Brambilla E, et al. Genetic changes in the spectrum of neuroendocrine lung tumors. Cancer 1999;85:600-7.

7. Costes V, Marty-Ane C, Picot MC, Serre I, Pujol JL, Mary H, et al. Typical and atypical bronchopulmonary carcinoid tumors: a clinicopathologic and Ki-67 labeling study. Hum Pathol 1995;26:740-5.

8. Durham JR, Nakhleh RE, Swanson PE, Fisher JR, Zarbo RJ. Proliferation markers MIB-1 and PCNA in pulmonary neuroendocrine tumors. Appl Immunochem 1995;3:174-83.

9. Bohm J, Koch S, Gais P, Jutting U, Prauer HW, Hofler H. Prognostic value of MIB-1 in neuroendocrine tumours of the lung. J Pathol 1996;178:402-9.

10. Rusch VW, Klimstra DS, Venkatraman ES. Molecular markers help characterize neuroendocrine lung tumors. Ann Thorac Surg 1996;62:798-809.

11. Laitinen KLJ, Soini Y, Mattila J, Paakko P. Atypical bronchopulmonary carcinoids show a tendency toward increased apoptotic and proliferative activity. Cancer 2000;88:1590-8.

12. Slodkowska J, Sikora J, Androsiuk W, Rudzinski P, Radomyski A. Lung carcinoids. Tumor angiogenesis in relation to clinicopathologic characteristics. Anal Quant Cytol Histol 1999; 21:267-72.

13. Travis WD, Colby TV, Corrin B, Shimosato Y, Brambilla E, et al. Histologic typing of lung and pleural tumors. 3rd ed. Berlin: Springer-Verlag; 1999.
14. Weidner N, Semple JP, Welch WR, Folkman J. Tumor angiogenesis and metastasis-correlation in invasive breast carcinoma. N Engl J Med 1991;324:1-8.

15. Granberg D, Wilander E, Oberg K, Skogseid B. Prognostic markers in patients with typical bronchial carcinoid tumors. J Clin Endocrinol Metab 2000;85:3425-30.

16. Folkman J. Tumor angiogenesis: therapeutic implications. N Engl J Med 1971;285:1182-6.

17. Holmgren L, O'Reilly MS, Folkman J. Dormancy of micrometastases: balanced proliferation and apoptosis in the presence of angiogenesis suppression. Nat Med 1995;1:149 53.

18. Weidner N, Carroll PR, Flax J, Blumenfeld W, Folkman J. Tumor angiogenesis correlates with metastasis in invasive prostate carcinoma. Am J Pathol 1993;143:401-9.

19. Barnhill RL, Piepkorn MW, Cochran AJ, Flynn E, Karaoli T, Folkman J. Tumor vascularity, proliferation, and apoptosis in human melanoma micrometastases and macrometastases. Arch Dermatol 1998;134:991-4.

20. Arbiser JL, Moses MA, Fernandez CA, Ghiso N, Cao Y, Klauber $\mathrm{N}$, et al. Oncogenic H-ras stimulates tumor angiogenesis by two distinct pathways. Proc Natl Acad Sci USA 1997;94:861-66.

21. Rak J, Mitsuhashi Y, Sheehan C, Tamir A, Viloraia-Petit A, Filmus J, et al. Oncogenes and tumor angiogenesis: differential modes of vascular endothelial growth factor upregulation in ras-transformed epithelial cells and fibroblasts. Cancer Res 2000;60:490-8.

22. Mazure NM, Chen EY, Laderoute KR, Giaccia AJ. Induction of vascular endothelial growth factor by hypoxia is modulated by a phosphatidylinositol 3-kinase/Akt signaling pathway in Ha-ras- transformed cells through a hypoxia inducible factor-1 transcriptional element. Blood 1997;90: 3322-31.

23. Bargmann CI, Weinberg RA. Oncogenic activation of the neu-encoded receptor protein by point mutation and deletion. EMBO J 1988;7:2043-52.

24. Parada LF, Tabin CJ, Shih C, Weinberg RA. Human EJ bladder carcinoma oncogene is homologue of Harvey sarcoma virus ras gene. Nature 1982;297:474-8.

25. Land H, Chen AC, Morgenstern JP, Parada LF, Weinberg RA. Behavior of myc and ras oncogenes in transformation of rat embryo fibroblasts. Mol Cell Biol 1986;6:1917-25.

26. Bargmann CI, Hung MC, Weinberg RA. Multiple independent activations of the neu oncogene by a point mutation altering the transmembrane domain of p185. Cell 1986;45: 649-57.

27. Serrano M, Lee H, Chin L, Cordon-Cardo C, Beach D, DePinho RA. Role of the INK4a locus in tumor suppression and cell mortality. Cell 1996;85:27-37.

28. Ziegler A, Leffell DJ, Kunala S, Sharma HW, Gailani M, Simon JA, et al. Mutation hotspots due to sunlight in the p53 gene of nonmelanoma skin cancers. Proc Natl Acad Sci USA 1993; 90:4216-20.

29. Bastian BC, LeBoit PE, Pinkel D. Mutations and copy number increase of HRAS in Spitz nevi with distinctive histopathological features. Am J Pathol 2000;157:96772.

30. Pal S, Claffey KP, Dvorak HF, Mukhopadhyay D. The von Hippel-Lindau gene product inhibits vascular permeability factor/vascular endothelial growth factor expression in renal cell carcinoma by blocking protein kinase C pathways. J Biol Chem 1997;272:27509-12.

31. Iliopoulos O, Levy AP, Jiang C, Kaelin WG Jr, Goldberg MA. Negative regulation of hypoxia-inducible genes by the von Hippel-Lindau protein. Proc Natl Acad Sci USA 1996;93: 10595-9. 
32. Sagawa M, Saito Y, Fujimura S, Linnoila RI. K-ras point mutation occurs in the early stage of carcinogenesis in lung cancer. Br J Cancer 1998;77:720-3.

33. Klafter R, Arbiser JL. Regulation of angiogenesis and tumorigenesis by signal transduction cascades: lessons from benign and malignant endothelial tumors. J Invest Dermatol Symp Proc 2000;5:79-82.

34. Gortz B, Roth J, Krahenmann A, de Krijger RR, MulettaFeurer S, Rutimann K, et al. Mutations and allelic deletions of the MEN1 gene are associated with a subset of sporadic endocrine pancreatic and neuroendocrine tumors and not restricted to foregut neoplasms. Am J Pathol 1999;154:429-36.
35. Przygodzki RM, Finkelstein SD, Langer JC, Swalsky PA, Fishback N, Bakker A, et al. Analysis of p53, K-ras-2, and C-raf-1 in pulmonary neuroendocrine tumors. Correlation with histological subtype and clinical outcome. Am J Pathol 1996; 148:1531-41.

36. Debelenko LV, Brambilla E, Agarwal SK, Swalwell JI, Kester JI, Kester MB, Lubensky IA, et al. Identification of MEN1 gene mutations in sporadic carcinoid tumors of the lung. Hum Mol Genet 1997;6:2285-90.

37. Couce ME, Bautista D, Costa J, Carter D. Analysis of K-ras, $\mathrm{N}$-ras, $\mathrm{H}$-ras, and p53 in lung neuroendocrine neoplasms. Diagn Mol Pathol 1999;8:71-9.

\section{Book Review}

Teffer A, editor: Primary Hematology, 472 pp, Totowa, NJ, Humana Press, 2000 (\$125.00).

This book, produced by a team of hematologists from Mayo Clinic, could be dubbed Mayo Clinic Hematology for non-hematologists. It stands out among the numerous other hematology books for its down-to-earth, practice-oriented tilt, methodical approach to common hematologic problems, and an excellent application of algorithmic diagnostic/treatment schedules. All these pearls of wisdom are taken directly from the time-tested routine practiced at Mayo Clinic, thus bringing to the reader not only the experience of several generations of experienced clinicians, but also implicitly the stamp of approval of one of the most famous medical institutions in the United States.

The book is concise but still comprehensive, covering essentially all aspects of hematology for the practicing physician. Key issues of diagnosis, differential diagnosis, and treatment are discussed for all major entities, such as anemias, leukemias, and bleeding disorders. Each topic is discussed systematically, leading the reader step- wise from the simple facts of diagnosis and clinical work-up, through the labyrinths of differential diagnosis, to choosing the logical, currently recommended therapeutic modalities. Items such as "easily overlooked problems," "associated conditions," and "general management recommendations" are frequently included and, for the sake of visibility, often these aspects of the text are presented in tabular or framed format. Currently used drugs are discussed thoroughly, together with the expected and less common adverse reactions. Two last chapters worth mentioning deal with ethical problems encountered in the practice of hematology and statistical methods.

This is an excellent book, and I plan to recommend ir to my residents and fellows. I hope that it will be read by general internists and family practitioners and clinical pathologists. It is an ideal guide on how hematology should be taught and practiced.

\author{
Nevena Damjanov \\ Temple University School of Medicine \\ Philadelphia, Pennsylvania
}

